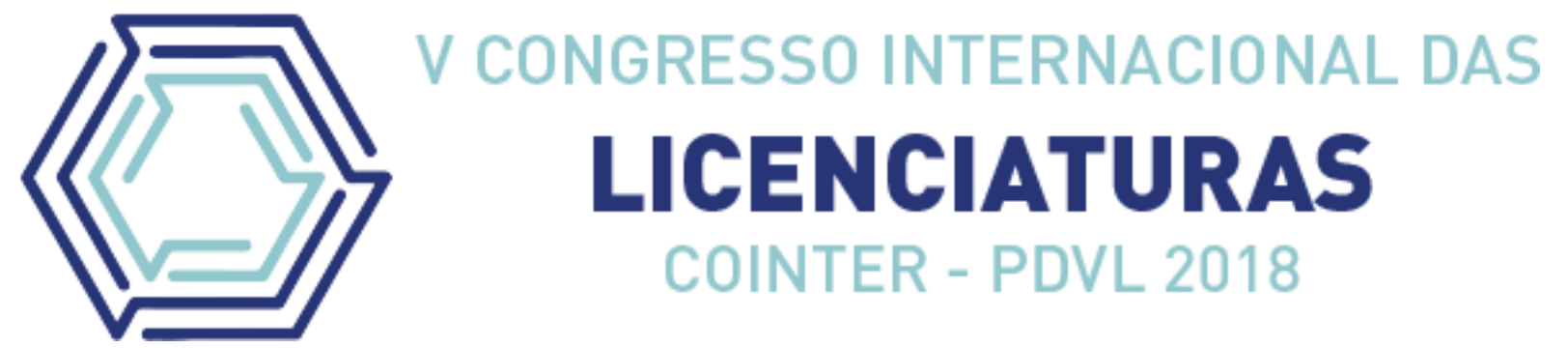

\title{
O JOGO DE TABULEIRO COMO RECURSO PARA A PROMOÇÃO DA INCLUSÃO NAS ESCOLAS
}

\section{THE BOARD GAME AS A RESOURCE FOR THE PROMOTION OF INCLUSION IN SCHOOLS}

\author{
Apresentação: Relato de Experiência
}

Bruna Moura Cardoso Sousa ${ }^{1}$;Gabrielle Cristina de Melo Oliveira ${ }^{2}$; Marcela Oliveira de Sousa $^{3}$; Alisson Abreu Rodrigues ${ }^{4}$; Joaquina Maria Portela Cunha Melo ${ }^{5}$

DOI: https://doi.org/10.31692/2358-9728.VCOINTERPDVL.2018.00297

\section{Introdução}

Atualmente os jogos são muito utilizados por educadores, por ser uma atividade que desperta o interesse entre os alunos pela disciplina. Segundo Soares (2010) A atividade lúdica, o jogo, é muito importante para a formação da criança e, na escola, este em geral é o espaço no qual a inclusão ocorrerá de forma mais natural.

Constatou-se através de pesquisas que atividades lúdicas como jogos de tabuleiro melhoram a autoestima, a concentração e o desempenho de alunos segundo Assis (2014). Desta forma estas práticas dinâmicas utilizadas pelo professor podem favorecer a inclusão de alunos surdos e deficientes auditivos, democratizando cada vez mais o ensino.

Conforme Almeida (2000), a ludicidade contribui e influencia na formação do aluno, possibilitando uma evolução constante no conhecimento. Contudo o mesmo somente será garantido se o educador estiver preparado para realizá-lo. Algumas vantagens do jogo são: fixação dos conteúdos já aprendidos de uma forma motivadora para o aluno, o jogo requer a participação ativa dos alunos na construção do seu próprio conhecimento, motiva os alunos pode ser utilizada para reforçar ou recuperar habilidades de que os alunos necessitem e permitem ao professor identificar, diagnosticar alguns erros de aprendizagem, as atitude e dificuldades dos alunos.

\footnotetext{
${ }^{1}$ Licenciatura em Ciências Biológicas, IFPI- Instituto Federal do Piauí, cardos.bmcs@gmail.com

${ }^{2}$ Licenciatura em Ciências Biológicas, IFPI- Instituto Federal do Piauí, gabriellecristina.melo@gmail.com

${ }^{3}$ Licenciatura em Ciências Biológicas, IFPI- Instituto Federal do Piauí, marcelaoss24@gmail.com

${ }^{4}$,Licenciatura em Ciências Biológicas, IFPI- Instituto Federal do Piauí, abreu.alisson96@gmail.com

${ }^{5}$ Especialista em LIBRAS, IFPI- Instituto Federal do Piauí, joaquina.cunha@ifpi.edu.br
} 


\section{VONGBESSO INTERACOONAL DAS LICENCIATURAS COINTER - PDVL 2018}

\section{Relato de Experiência}

Alunos com deficiência auditiva encontram diversos tipos de obstáculos para inclusão nos ambientes sociais da escola, desde a falta de comunicação com os outros alunos, até a compreensão do conteúdo, mesmo com a presença do intérprete, pois segundo o autor "a falta de sinais específicos e a falta de domínio do intérprete em relação aos conceitos científicos, dificulta a compreensão do aluno com surdez" (VARGAS E GOBARA, 2011, p.6), vale ressaltar que quando há ausência de sinais específicos para os termos científicos, utiliza-se a datilologia como recurso explicativo.

A partir do problema, a prática realizada teve o intuito de facilitar a aprendizagem no ensino de ciências em assuntos de botânica, utilizando a Língua Brasileira de Sinais (LIBRAS). A partir do proposto foi confeccionado um jogo de tabuleiro contendo placas com imagens de plantas, frutas e legumes, bem como uma tabela de regras que deveriam ser seguidas durante o jogo.

Durante a exposição do tabuleiro ocorreu a explicação em sinais, e quando necessário em datilologia dos significados de cada placa, facilitando assim a aprendizagem de participantes leigos, onde, de acordo com a apresentação, houve uma interação de aprendizado cujo o retorno foi positivo e, além de obterem o aprendizado da botânica, houve também o aprendizado da LIBRAS. Assim, foi possível observar uma sensibilização de ambas as partes, uma vez que a maioria do público eram alunos, professores, e demais servidores da instituição no qual ainda não havia tido contato com a LIBRAS.

Como forma de avaliação utilizou-se o jogo de tabuleiro, e dados, para a exequibilidade do mesmo. Na triagem do lúdico os dados eram jogados, e a numeração apresentada se referia a alguma das placas representativas, onde a resposta deveria ser realizada em sinais. Neste contexto, o público-alvo foram estudantes, professores e servidores, para sensibilização à inclusão através da experiência, favorecendo a inclusão social de alunos surdos, Silva, et.al. (2009). 


\section{LICENCIATURAS COINTER - PDVL 2018}

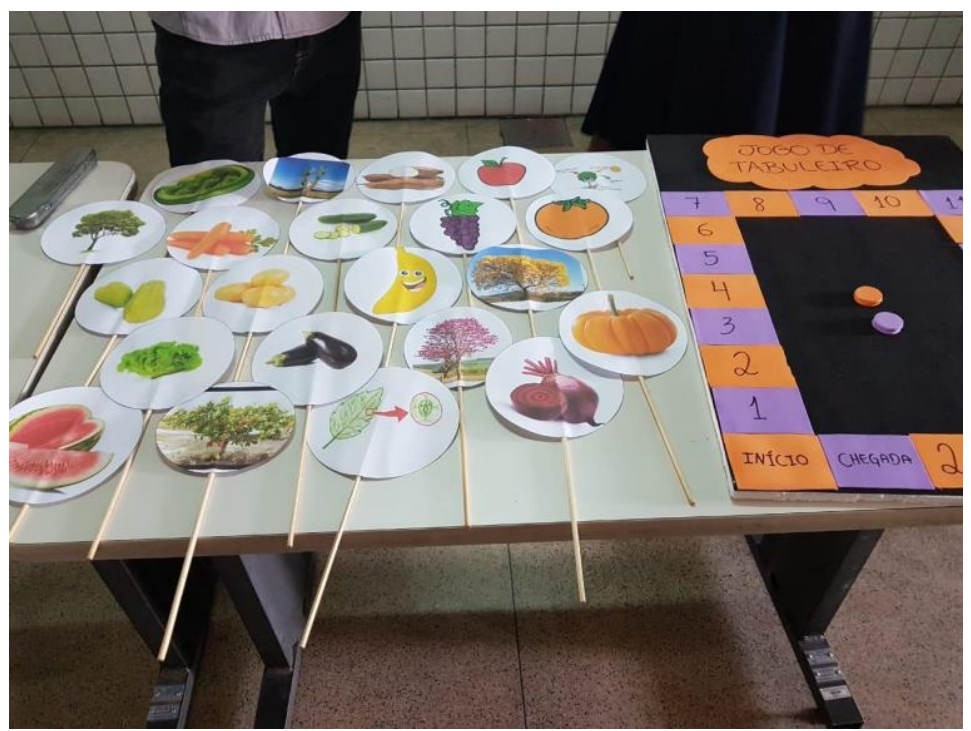

Imagem 1: placas contendo imagens simples para desenvolvimento da prática. Fonte: própria.

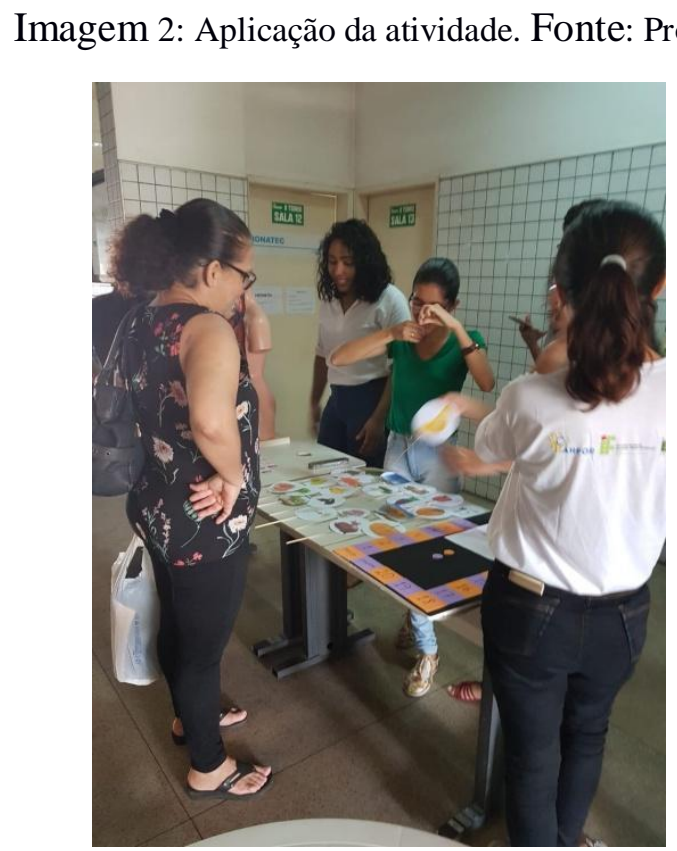

\section{Considerações}

Através dessa proposta, é possível trabalhar a produção de lúdicos e práticas dinâmicas que possam favorecer a sensibilização e a inclusão de pessoas com deficiências físicas e mentais (não 


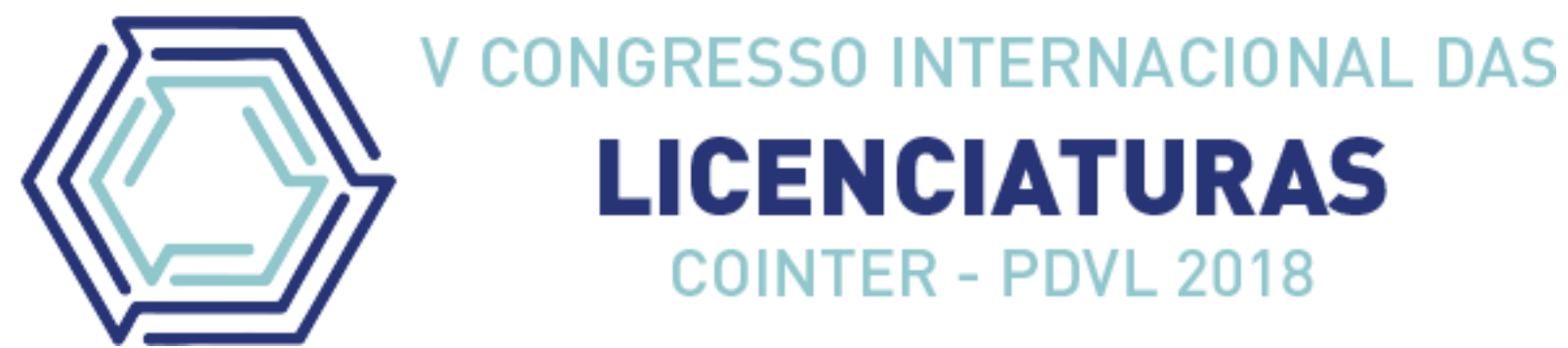

somente a surdez), a exposição para alunos não deficientes possibilita um olhar diferenciado para questões sociais, que dificultam a realização de um ensino democrático e inclusivo. Tivemos a participação de um público que tiveram a oportunidade de aprender um pouco de Libras através do nosso jogo, e com isso talvez despertar o interesse e a sensibilização dos mesmos. Diante da grande aceitação do público obteve-se resultado positivo no que fora exposto.

\section{Referências}

ASSIS, Cleber Francisco de. Jogos de Tabuleiro como Recurso Metodológico para Aulas de Matemática no Segundo Ciclo do Ensino Fundamental. 2014. 76f. Dissertação (Mestrado) Instituto de Matemática da Universidade Federal da Bahia. Departamento de Matemática. Salvador. Disponível em : <http://w3.impa.br/ tertu/archives/dissertacoes/Dissertacao_Cleber.pdf > acesso em: 20 Set 2018.

SOARES, Edna Machado. A ludicidade no processo de inclusão de alunos especiais no ambiente educacional. Rio de Janeiro. 2010. 33f. Disponível em <www.ffp.uerj.br/arquivos/dedu/monografias/EMS.2.2010.pdf > acessado em: 20 Set 2018.

SILVA, Silvana Correia; ARAÚJO, Antonieta; CASTELAR, Marilda; MENDES, Nicoleta. As contribuições da psicologia na educação de surdos: o caso do Centro de Educação Especial do Estado da Bahia. Salvador: EDUFBA, 2009, pp. 171-190. Disponível em: <http://books.scielo.org/id/rp6gk/pdf/diaz-9788523209285-17.pdf> acessado em: 20 set 2018.

VARGAS, Jaqueline Santos; GOBARA, Shirley Takeco. O aluno surdo nas escolas regulares: dificuldades na inclusão. $2011 . \quad$ Disponivel <www.nutes.ufrj.br/abrapec/viiienpec/resumos/R1012-1.pdf> acessado em 20 Set 2018. 